\title{
Os Métodos de Controle da Utilização da Obra Protegida por Direitos de Autor
}

\author{
Copyright-Protected Use Control Methods
}

\author{
Iracema Fazio
}

UNIME Lauro de Freitas. BA, Brasil.

E-mail: iracema.fazio@kroton.com.br

\begin{abstract}
Resumo
Este artigo tem o propósito de estudar os métodos de controle de utilização da obra, identificando os atos de restrição à utilização da obra implementados pelas medidas tecnológicas de proteção. Assim, pretende analisar o regime jurídico das medidas tecnológicas de proteção implementado no Digital Millenium Copyright, bem como no âmbito do Marco Regulatório da União Europeia e da Legislação Autoral Brasileira e verificar os seus impactos no regime de utilizações livres, especialmente, no que concerne à cópia privada digital e aos atos de neutralização das medidas tecnológicas de proteção.
\end{abstract}

Palavras-chave: Direito de Autor. Cópia Privada Digital. Medidas Tecnológicas de Proteção.

\begin{abstract}
This article aims to study the control methods on the use of work, identifying the restriction acts on the use of the work implemented by technological protection measures. It intends to analyze the legal regime of the technological protection measures implemented in the Digital Millenium Copyright, as well as, within the scope of the European Union Regulatory Framework and the Brazilian Copyright Legislation, and to verify their impacts on the free use regime, especially regarding digital private copying and neutralization acts of technological protection measures.
\end{abstract}

Keywords: Copyright. Digital Private Copy. Technological Protection Measures.

\section{Introdução}

A via tecnológica de proteção das obras intelectuais consiste em utilizar uma série de mecanismos que permitem identificar os materiais suscetíveis de serem protegidos pelos direitos de autor e que controlam o uso que se faz destes, evitando-se perdas econômicas para o titular de direitos de exploração econômica, assim como a violação das faculdades pessoais dos seus autores (FERNÁNDEZ-MOLINA; PEIS, 2001).

Estes sistemas, que recebem inúmeras denominações, como ECMS (Electronic Copyright Management Systems Sistemas de Gestão Eletrônica de Direitos de Autor), ERMS (Electronic Rights Management Systems - Sistemas de Gestão de Direitos Eletrônicos) ou DRMS (Digital Rights Management Systems - Sistemas de Gestão de Direitos) permitem agora a utilização de barreiras, ou seja, métodos de proteção da propriedade habituais em outros setores, porém que até agora não eram tecnicamente possíveis para o direito de autor (O'ROURKE, 1998).

Saliente-se, contudo, que o termo medidas tecnológicas é diverso destes termos que em geral compreendem sistemas de informação para a gestão eletrônica de dispositivos; tratandose, assim, de realidades distintas.

Note-se que a informação para a gestão eletrônica de direitos consubstancia-se em uma realidade mais alargada, uma vez que permite a identificação de conteúdo protegido e a eficácia da utilização de obras, segundo a lei e as diretrizes impostas pelos titulares de direitos (HUGENHOLTZ; GUIBAULT; GEFFEN, 2003).

Refira-se que a distinção entre tais sistemas de informação para a gestão eletrônica e as medidas tecnológicas reside no fato de que estas se destinam a restringir ou a impedir o uso da obra, já os sistemas moldam e regulam a utilização de obras no ambiente digital, servindo-se tipicamente de medidas tecnológicas com o fim de gestão, por isso não se restringem ou se confundem com aquelas (HUGENHOLTZ; GUIBAULT; GEFFEN, 2003).

Pondere-se que o impacto destes sistemas de gestão eletrônica será bastante reduzido, por isso se fez a opção no presente artigo por realizar apenas o aprofundamento em matéria dos mecanismos tecnológicos de proteção. Aliás, é pela utilização destes mecanismos que se avoluma o impacto no respeito aos limites impostos ao titular de direitos de autor e mais especificamente no que diz respeito ao limite da cópia privada.

Deste modo, o presente artigo objetiva estudar os métodos de controle da utilização da obra protegida por direitos de autor, bem como, os mecanismos tecnológicos utilizados para efetuar-se o controle sobre os atos de reprodução no ambiente digital da obra protegida pelo direito de autor, com o enfoque 
nos atos de utilização permitidos, ou seja, no âmbito do uso privado.

Para o efeito, pretende identificar os métodos de controle de utilização da obra, estudar os atos de restrição à utilização da obra implementados pelas medidas tecnológicas de proteção, analisar o regime jurídico das medidas tecnológicas de proteção implementado no Digital Millenium Copyright e no âmbito do Marco Regulatório da União Europeia, confrontando com a Legislação Autoral brasileira e, assim, verificar os seus impactos no regime de utilizações livres, especialmente, no que concerne à cópia privada digital e aos atos de neutralização das medidas tecnológicas de proteção.

Desse modo, será por fim estudado neste artigo o razoável equilíbrio entre o regime de proteção contra os atos de neutralização das medidas tecnológicas e a cópia para uso privado.

\section{Desenvolvimento}

\subsection{Os métodos de controle de utilização da obra}

De modo bastante despretensioso, em nível técnico sobre a matéria, assinale-se que são quatro os métodos de controle de utilização da obra (VICENTE, 2006). Nesse sentido, é possível realizar as seguintes atividades de controle sobre a obra, impedir a modificação da obra, prevenir ou restringir determinados usos, impor um número máximo de utilizações ou somente controlar o simples acesso à obra. Observe-se que tais atos de controle sobre a obra poderão vir a ser exercidos de modo isolado ou ainda em conjunto (RAMALHO, 2011).

$\mathrm{Na}$ verdade, agrupando-se estas quatro modalidades de controle em dois grupos com métodos semelhantes, permitese ao titular do direito de autor fazer uso de medidas de controle de acesso e de cópia.

Destacam-se entre as medidas de controle de acesso, aquelas que consistem tão-somente na introdução de uma palavra-chave para acesso ao endereço na internet, no qual a obra se encontra disponível; mas, também, há outros mais complexos, como: CSS - Content Scrambling System ${ }^{1}$ e o AACS - Advanced Access Content System ${ }^{2}$ (BARRY, 2004).

Quanto às medidas de controle de cópias mais utilizadas se tem o SCMS - Serial Copy Management System ${ }^{3}$, o SACD - Super Audio Compact Disc ${ }^{4}$ ou simplesmente aqueles que limitam a cópia a uma determinada espécie de equipamento ${ }^{5}$. Como também as tatuagens eletrônicas ou marcas de água, que muito embora utilizadas largamente para a gestão eletrônica de direitos revelam, na verdade, um eficiente método de controle das utilizações; na medida em que acrescem à obra uma marca, que não a altera e resiste ao tratamento da informação contida no suporte, ou até mesmo a sua modificação (JOHNSON, 2009).Observe-se que a proteção legal destes mecanismos tecnológicos surgiu com os Tratados da Organização Mundial da Propriedade Intelectual de 1996. O art. 11 do Tratado sobre Direitos de Autor desta Organização, intitulado «obrigações relativas às medidas tecnológicas» estabelece que as partes contratantes devem proporcionar a adequada proteção jurídica e os recursos jurídicos efetivos contra os atos de neutralização das medidas tecnológicas.

Note-se que o referido dispositivo do Tratado sobre Direitos de Autor desta Organização transfere a responsabilidade da disciplina sobre o regime jurídico das medidas tecnológicas para os Estados. Entretanto, disciplina, prontamente, que devem os Estados legislar sobre os atos que visam neutralizar as medidas tecnológicas. O que implica em reconhecer a vontade do legislador internacional em impor sanções diversas aos atos de neutralização das medidas tecnológicas, que devem ser reguladas pelos Estados, de acordo com o seu regime jurídico interno.

Retira-se, portanto, do comando legal internacional, que todos os Estados, ao firmarem este Tratado, assumiram a obrigação de proteger legalmente as medidas tecnológicas efetivas. E, não só! Pode-se, sem dúvidas, concluir, também, pela obrigação dos Estados em prever um regime jurídico adequado contra os atos que visam neutralizar estes mecanismos tecnológicos de proteção.

Note-se que assim possível é se conjugarem as medidas tecnológicas com os limites do direito de autor, uma vez que, como observa Koelman (2001), não se encontra proibida a neutralização das medidas tecnológicas, a fim de consumar atos permitidos, fundados em um dos limites do direito de autor, a exemplo do limite da cópia privada (KOELMAN, 2000)

A definição destas medidas tecnológicas de proteção no Tratado da Organização Mundial da Propriedade Intelectual sobre Direitos de Autor leva em consideração se são estas medidas «efetivas», «utilizadas pelos autores em relação ao exercício dos seus direitos nos termos do presente Tratado ou da Convenção de Berna» e se «restringem atos que não estão autorizados pelos autores em questão ou permitido por lei».

Sem embargo, algumas discussões foram enfrentadas sobre a definição adotada pelo legislador internacional neste art. 11. Em primeiro plano se debateram as razões do uso da

1 Tecnologia que corresponde a uma cifragem baseada em um sistema de chaves que se encontram no equipamento e no suporte. Esta espécie de tecnologia havia sido especialmente concebida para a proteção de DVDs.

2 Tecnologia que consiste em uma cifragem com um sistema de chaves localizado tanto no equipamento como no suporte de armazenamento, mas que utiliza avançada tecnologia de criptografia.

3 Sistema que impede a cópia de segunda geração, ou seja, a cópia realizada através de outra cópia.

4 Sistema que fixa uma marca de água no suporte, e que desaparece quando este é copiado, impedindo leitura da cópia.

5 Sistema que era utilizado pela Apple, no qual o arquivo quando adquirido em uma plataforma web, como por exemplo o arquivo de áudio comprado no iTunes, não podia ser copiado para outros equipamentos que não o computador ou o iPod, impedindo ainda o envio do arquivo pela internet, por exemplo através de uma rede peer-to-peer. 
expressão «efetivas» para qualificar tais medidas tecnológicas.

Sobre este debate, afirmou-se, que o propósito da inclusão do requisito da efetividade era o de não assegurar proteção legal àquelas medidas tecnológicas facilmente neutralizadas, ou as que facultem a sua neutralização por um mero acidente (LUCAS, 1998; KOELMAN, 2001).

No entanto, houve também quem acrescenta que o propósito deste requisito foi o de destacar a desnecessidade de se atribuir proteção legal àquelas medidas que, de fato, sejam completamente eficientes, já que não neutralizadas em seu todo. Justificando-se, inclusive, este posicionamento, pela utilização, por duas vezes, da expressão efetiva no art. 11 do Tratado da Organização Mundial da Propriedade Intelectual sobre Direitos de Autor.

Como foi debatido na ação promovida pela Universal City Studios, Inc. e mais sete outros estúdios em face de Shawn Reimerdes, Eric Corley, Roman Kazan e mais 2.600 empresas, pela distribuição do programa DeCSS, capaz de descriptografar conteúdos protegidos pelo CSS - Content Scrambling System, ou seja, por uma medida tecnológica de proteção comumente utilizada para a proteção dos conteúdos gravados em DVDs.

As empresas litigantes sustentaram que o programa DeCSS para neutralizar o CSS foi produzido e lançado sem autorização da DVD CCA, a associação responsável pelo controle de cópias de DVDs. Os três demandados alegaram em sua defesa que as suas ações não violam o Digital Millennium Copyright Act (Lei dos Direitos Autorais do Milênio Digital) e, em qualquer caso, que este corpo normativo, aplicado aos programas de computador, ou ao seu código, viola a Primeira Emenda. Justificaram, esta defesa, com o argumento de que o código do programa de computador, independentemente de sua função, trata-se de um «discurso», por isso, deve ser protegido constitucionalmente, não se admitindo a sua regulação.

Em primeiro grau, o Juiz Lewis A. Kaplan decidiu a favor das oito grandes companhias da indústria do cinema, afirmando ainda a constitucionalidade do Digital Millennium Copyright Act, e concluiu que os conflitos de interesses concorrentes como este são resolvidos pelo Congresso. Acrescentando, ainda, que o Congresso resolveu esse choque em favor dos demandantes, em função das características peculiares dos programas de computador propícias a burlar criptografia e outras medidas de controle de acesso. Entendendo, por fim, que Digital Millennium Copyright Act é aplicado na postagem e ligação, não violando assim a Primeira Emenda (ESTADOS UNIDOS DA AMÉRICA. Tribunal de Apelações. 2. ${ }^{\circ}$ Circuito. 273 F.3d 429, 2000).

Não satisfeitos, os três demandados recorreram desta decisão ao Tribunal de Apelação, que embora tenha confirmado a decisão de primeiro grau, enfatizou que concordava com o argumento dos demandantes de que os programas de computador são uma forma de expressão, protegida, independentemente de se fazerem representar pelo seu código-fonte ou pelo seu código-objeto. Em conclusão, o Tribunal afirmou que o fair use nunca foi considerado uma garantia de acesso a material protegido por direitos de autor (ESTADOS UNIDOS DAAMÉRICA. Tribunal de Apelações. 2. ${ }^{\circ}$ Circuito. 273 F.3d 429, 2001).

Em seguida, passou-se à discussão sobre a necessidade de as medidas tecnológicas de proteção serem utilizadas pelos autores em relação ao exercício dos seus direitos. $\mathrm{Na}$ verdade, o sentido deste segundo critério pretende assegurar que a utilização das medidas tecnológicas de proteção fiquem restritas aos titulares de direitos de autor sobre a obra protegida.

Resulta, portanto, deste requisito, que o art. 11, do Tratado da Organização Mundial da Propriedade Intelectual sobre Direitos de Autor não será aplicado às medidas tecnológicas de proteção fora do âmbito da legislação de direitos de autor, ou às obras que se encontram no domínio público. Pois que, nesse sentido, a utilização pelos autores destas medidas não se encontra relacionada ao exercício dos seus direitos, assegurados pelas leis de tutela autoral.

Quanto ao terceiro requisito, em uma interpretação literal do referido dispositivo da legislação internacional em comento se observa que este é cumulativo ao segundo, ou seja, exige-se dos titulares de direitos de autor, no exercício dos seus direitos regulados no Tratado da Organização Mundial da Propriedade Intelectual sobre Direitos de Autor, que a utilização de medidas tecnológicas de proteção, em suas obras, seja restrita aos atos não autorizados ou permitidos na lei.

O que implica em afirmar que os atos de neutralização das medidas tecnológicas de proteção, praticados dentro dos limites do uso privado, não estarão proibidos nos termos do art. 11 do Tratado da Organização Mundial da Propriedade Intelectual sobre Direitos de Autor. Por consequência lógica, estarão proibidos os atos de neutralização das medidas tecnológicas de proteção, cuja finalidade escape aos limites do uso privado (KOELMAN, 2000).

Observa-se, assim, que a exigência destes requisitos para se admitir o uso lícito das medidas tecnológicas de proteção, que reside em assegurarque deve existir um equilíbrio entre o âmbito de proteção destas medidas e a proteção dos direitos de autor.

Ademais, cumpre-se indagar se a exigência de proteção legal adequada, disciplinada no art. 11 do Tratado da Organização Mundial da Propriedade Intelectual sobre Direitos de Autor, implica necessariamente na disciplina, dos direitos de autor, de um regime jurídico específico, para regular as medidas anti-neutralização?

Sinceramente, não aparenta ser este o sentido da norma. O art. 11 do Tratado da Organização Mundial da Propriedade Intelectual sobre Direitos de Autor não faz exigência da integração de um regime jurídico específico para as medidas anti-neutralização, na legislação de proteção autoral. Resultado, desta interpretação é se constatar que os Estados signatários do referido Tratado se encontram livres para estabelecer qualquer modalidade de proteção legal. 


\subsection{O Razoável Equilíbrio entre o Regime de Proteção Contra os Atos de Neutralização da Medidas Tecnológicas e a Cópia para uso Privado}

Cumpre-se, ainda, investigar se toda e qualquer medida irá alcançar o regime de proteção jurídica conferido pela lei (LESSIG, 1999). Melhor, é preciso adequar a proteção jurídica ao propósito técnico para o qual estas medidas foram criadas; evitando-se assim distorções no sistema, conforme o já anteriormente analisado.

Todavia, antes de enfrentar o tema, convém esclarecer quais são os elementos desta proteção. Assim, faz-se necessário estudar o objeto da proteção, a intenção do agente, bem como o âmbito de proteção, verificando-se, por fim, a possibilidade de reflexo desta proteção conferida às medidas tecnológicas com o limite da cópia privada.

Sobre o objeto da proteção se aponte que os ordenamentos jurídicos de um modo geral revelam que este pode compreender toda e qualquer medida tecnológica eficiente. Por isso, importante é decifrar juridicamente o que se entende por medida tecnológica e, consequentemente, a delimitação das eficientes medidas.

Este foi, inclusive, um cuidado tomado pelo legislador português em seu art. $217 .^{\circ}$, refletindo o espírito da Diretiva 2001/29/CE no n. ${ }^{\circ} 3$ do seu art. $6 .^{{ }^{\circ} 6}$; que todavia, não observou o problema que criou ao não distinguir as medidas de controle das medidas de acesso. Na verdade, a proteção jurídica apenas deveria recair sobre as medidas de controle de cópia, pois são estas que impedem ou restringem a reprodução da obra. Para as medidas de controle de acesso, portanto, não se deveria ter outorgado a proteção legal; uma vez que este controle não representa um exclusivo autoral.

Ademais, equivocou-se o legislador português no momento da transposição da Diretiva 2001/29/CE, por isso a previsão portuguesa no seu art. $217 .^{\circ}$ se refere a atos não autorizados pelo titular do direito. O referido texto comunitário define as medidas de caráter tecnológico como toda aquela destinada "a impedir ou restringir actos, no que se refere a obras ou outro material, que não sejam autorizados pelo titular de um direito de autor ou direitos conexos previstos por lei ou do direito sui generis previsto no capítulo III da Directiva 96/9/CE”.

Sem embargo, o titular do direito de autor apenas poderá impedir ou restringir estes atos quando consubstanciem o exercício de direitos que lhe tenham sido previamente outorgados por lei. O que alarga a compreensão da Diretiva 2001/29/CE, já que aparentemente se confere ao titular do direito um poder imperativo, que em teoria permitir-se-ia aferir da licitude do ato.

Observe-se que o legislador português, na verdade, pretendeu atender com o uso das medidas tecnológicas tanto a proteção no mundo analógico, como no ambiente digital. Enquanto no ambiente analógico a posse do suporte aduz propriedade, no ambiente digital o uso das medidas tecnológicas destinar-se-ia ao controle de acesso à obra.

Claramente, trata-se de uma posição equivocada, pois o acesso se consubstancia apenas em um meio de exercer o direito e em alguns casos de facilitar a circulação da obra no comércio, portanto não pode corresponder ao exercício de um exclusivo autoral, escapando assim da sua esfera de proteção.

Registre-se para além disso que a restrição do acesso à obra em um determinado protocolo, ou seja, em um formato específico que somente pode ser executado em uma plataforma tecnológica particular, não se apresenta de todo razoável a defesa de controle sobre os atos de acesso à obra em um determinado formato.

Assim, restringir o acesso a determinada obra, por exemplo que circula em um formato .jpg ou .pdf, não corresponde a um direito exclusivo, mas sim a um rigor de funcionalidade técnica que foi imposto. Portanto impedir o utilizador de transferir uma imagem do formato jpg para pdf, não confere uma proteção acrescida à imagem em si. Nessa ordem de ideias, na verdade, criam-se monopólios não desejáveis de operações nos diversos formatos.

Oportuno faz-se ainda destacar, que uma medida tecnológica será todo o mecanismo que tem por objetivo impedir ou restringir atos de utilização relativos às obras, entendidas estas como as criações intelectuais às quais é outorgada proteção ao nível do direito de autor.

Certo é, neste sentido, que uma medida tecnológica aposta em uma obra não protegida, seja essa não meritória de proteção $a b$ initio, como por exemplo, o caso de notícias do dia e relatos de acontecimentos diversos com caráter de simples informações de qualquer modo divulgados ou tenha essa enfrentado resultado não protegido, pois por exemplo caiu em domínio público, não sendo cabível na definição legal de medida tecnológica objeto da proteção, pode, como tal, ser neutralizada sem qualquer sanção civil.

Pondere-se, que se deve entender por medida tecnológica eficaz aquela destinada a proteger a obra protegida pelo direito de autor, construindo-se a sua estrutura técnica de modo a garantir, razoável e proporcionalmente, este objetivo de proteção da criação intelectual. O que implica aduzir que será eficaz a medida tecnológica que exercer alguma espécie de controle sobre o uso da obra protegida e, ainda, impedir a sua neutralização por um utilizador médio.

O legislador comunitário sobre o tema foi mais além do que o português, já que acrescentou à noção de medida

6 Assim dispõe a Diretiva 2001/29/CE: As medidas de carácter tecnológico são consideradas «eficazes» quando a utilização da obra ou de outro material protegido seja controlada pelos titulares dos direitos através de um controlo de acesso ou de um processo de protecção, como por exemplo, a codificação, cifragem ou qualquer outra transformação da obra ou de outro material protegido, ou um mecanismo de controlo da cópia, que garanta a realização do objectivo de proteç̧ão. Conselho da Europa. Parlamento Europeu. Disponível em: $<$ http://eur-lex.europa.eu/LexUriServ/LexUriServ. do?uri=OJ:L:2001:167:0010:0019:PT:PDF>. 
tecnológica eficaz a previsão de que não deverá esta impedir o funcionamento normal dos equipamentos electrônicos e o seu desenvolvimento tecnológico.

Cuidando agora da intenção do agente que corresponde ao elemento subjetivo do problema, cabe indagar se a ação do sujeito que neutralizou o mecanismo tecnológico de proteção é dolosa ou não, ou seja, verificar se o agente desconhecia ou não que a sua ação compreendeu um ato de neutralização de uma medida tecnológica de proteção.

Esta análise se mostra importante, especialmente no ordenamento jurídico português, em função da previsão do art. 218. ${ }^{\circ}$ do Código de Direito de Autor e Conexos de Portugal, que regulamenta penalmente a matéria, estabelecendo a pena de prisão até um ano ou com pena de multa até 100 dias, para quem, não estando autorizado, neutralizar qualquer medida eficaz de carácter tecnológico, sabendo isso ou tendo motivos razoáveis para o saber.

Dequalquersorte, apresenta-se inteiramente desproporcional as sanções aplicadas pela legislação autoral portuguesa para quem realiza o ato de neutralização, independentemente da análise sobre a sua intenção; já que a consequência destas para o utilizador, beneficiário dos limites que a lei outorga, é a impossibilidade do exercício da garantia da cópia privada.

O efeito destas medidas é de uma gravidade extrema, já que para além da técnica jurídica não ter sido arrazoada, como fez por exemplo o legislador australiano em seu texto autoral ao prever exceções às mesmas, exclui completamente o exercício das limitações garantidas pela lei (ASCENÇÃO, 2008, 2009). Trata-se de uma afronta que deve ser apagada de imediato do ordenamento jurídico, em especial o português, em virtude da sua índole penal.

Quanto ao âmbito de proteção das medidas tecnológicas se esclareça que o mesmo ocupa-se por um lado em proibir os atos de neutralização de tais medidas e, por outro, em sancionar os atos preparatórios, que poderão se consubstanciar em uma infração, conforme a disciplina do art. $219 .^{\circ}$ da legislação autoral portuguesa e o comando do n. ${ }^{\circ} 2$, do art. 6. ${ }^{\circ}$ da Diretiva 2001/29/CE. Refira-se, que a punição aos atos preparatórios se encontra aberta tão-somente para aqueles que tenham finalidade comercial; autorizando-se, portanto, os atos de natureza privada.

Observe-se que a adoção de uma proteção legal para as medidas tecnológicas apresenta inúmeros fundamentos, inclusive, alguns justificados no próprio conteúdo de proteção do direito de autor. Assim, cumpre-se apenas identificar os que se reputam mais importantes e relevantes para a problemática desta investigação.

Nesta investigação, a proposta de análise dos fundamentos das medidas tecnológicas segue a compreensão de Ramalho
(2011), para quem a utilização das medidas tecnológicas de proteção compreende «uma forma de diminuir os custos de evitar violações do direito». É assim que a autora se preocupa em estudar os «benefícios da sobreproteção conferida pelo regime legal» que se compreendem entre o crescimento do mercado, a possibilidade de discriminação de preços, a diminuição dos custos de transação e a possível diminuição do preço da obra. Ademais, estuda a autora as «vantagens de uma subproteção», identificando-as como liberdade das obras no domínio público, liberdade de mercado, equilíbrio entre o caráter público e privado do bem intelectual, possível obstáculo ao aumento do preço da obra, falibilidade das medidas tecnológicas e imperfeição contratual (RAMALHO, 2011).

Aponte-se, por conseguinte, a proteção conferida pelo direito de propriedade reconhecida constitucionalmente, pois que permite excluir da proteção das medidas tecnológicas inseridas no bem intelectual não protegido, como por exemplo, aquele de domínio público. Portanto, se existe propriedade privada a ser protegida, a medida tecnológica se encontra carente de fundamento, permitindo-se a sua neutralização, sem afronta à lei (LOPES, 2005).

Podem as medidas tecnológicas compreenderem-se, também, como uma tutela preventiva, ou seja, antecipando uma proteção anteriormente à consumação da violação do exclusivo autoral; como, ainda uma proteção da liberdade da empresa e da iniciativa econômica.

Todavia, apresenta-se crucial para o deslinde do problema em causa entender se a proteção conferida pela lei para as medidas tecnológicas superam a proteção garantida à cópia privada. Deste modo, reputa-se necessária esta análise para compreender se existe afetação do exercício da garantia da cópia privada como limite pelo direito de autor que confere proteção jurídica às medidas tecnológicas de proteção.

Evidentemente que a Diretiva 2001/29/CE contribuiu de sobremaneira para a discussão deste problema, pois diante da necessidade de regulamentar os novos atos de reprodução, decorrentes do imperativo das novas tecnologias, acabou por reforçar a proteção do exclusivo ${ }^{7}$. Em passos ainda mais largos, como já referido andou o legislador português, que trouxe a proteção penal para garantir a manutenção da medida tecnológica de proteção ${ }^{8}$.

Frise-se que a previsão da proteção das medidas tecnológicas na Diretiva 2001/29/CE deixou a cargo de cada um dos Estados-membros a responsabilidade por determinar o âmbito de proteção dessa, respeitando-se os limites internos estabelecidos ao exclusivo autoral. Assim, cabe a regulamentação das medidas tecnológicas salvaguardando o limite da cópia privada a cada um dos Estados-membros. Por isso, dado este alargamento de espaço, para o reforço

7 Vd. arts. 5. ${ }^{\circ}$ e 6. ${ }^{\circ}$ da Diretiva 2001/29/CE. EUROPA. Disponível em: <http://eur-lex.europa.eu/LexUriServ/LexUriServ.do?uri=OJ:L:2001:167:001 0:0019:PT:PDF>.

8 Vd. art. 218. ${ }^{\circ}$ do Código de Direitos de Autor e Direitos Conexos português. PORTUGAL. Código de Direito de Autor e Conexos de Portugal. Disponível em $<$ http://www.dgpj.mj.pt/sections/leis-da-justica/livro-iii-leis-civis-e/leis-civis/direito-de-autor-e/>. 
da proteção do exclusivo, pela proteção legal das medidas tecnológicas, para muitos autores encerram o surgimento de um novo direito de exclusivo (BALKIN, 2004).

Neste sentido, anote-se a curiosa solução dada pelo legislador autoral português no n. ${ }^{\circ} 3$, do seu art. 221. ${ }^{\circ}$, como medida de conferir superioridade jurídica ao limite da cópia privada sobre as medidas tecnológicas de proteção, ou seja, a legislação portuguesa seguindo o comando da Diretiva 2001/29/CE em respeitar os limites legais ao direito de autor, criou uma situação no mínimo constrangedora.

Assim, todas as vezes que o utilizador pretender neutralizar uma medida tecnológica de proteção deverá socorrer-se ao IGAC - Inspecção Geral das Actividades Culturais solicitando a devida autorização, pois demonstra «que uma medida eficaz de carácter tecnológico impede ou restringe o uso ou a fruição de uma utilização livre por parte de um beneficiário que tenha legalmente acesso ao bem protegido.

Sem embargo, esta solução é extremamente desproporcional e desarrazoada. Imagine o constrangimento do utilizador ser obrigado a se dirigir a este organismo da administração para demonstrar que foi presenteado no Natal com um DVD adquirido pela sua tia-avó em Paris, em uma das lojas da FNAC, mas que não disponibiliza de equipamento adequado para a leitura deste suporte físico que contém um mecanismo tecnológico de proteção e, por isso necessita do original que espera lá ter sido depositado! Claro está, completo absurdo lógico e jurídico, outra não pode ser a qualificação para esta solução legal (SIMÕES, 2009).

O desequilíbrio da solução é frontal, pois enquanto os titulares de direitos de autor podem livremente fazer uso dos mecanismos tecnológicos de proteção, os utilizadores apenas poderão realizar atos de cópia para uso privado mediante a atuação de terceiros, neste caso do IGAC - Inspecção Geral das Actividades Culturais; pois, impedidos estão de neutralizar a tecnologia.

Sem dúvidas, é de fundamental importância uma revisão da legislação, neste particular, para que se possa restaurar o equilíbrio desejado entre interesses público e privado nas relações autorais.

Esta medida de reequilíbrio é possível mesmo em nível da Diretiva 2001/29/CE, já que esta garante a cada Estado-membro a adoção de medidas que visam o respeito aos limites do direito de autor. Assim, a transposição desta Diretiva deveria adotar a medida obrigatória aos titulares do direito de autor de respeito ao limite da cópia privada. O fundamento desta obrigação se encontra na disposição do Considerando 51 do referido texto comunitário, que determina a aplicação da proteção jurídica das medidas tecnológicas sem prejuízo da ordem pública, remetendose ainda à disciplina do art. 5. ${ }^{\circ}$ da Diretiva 2001/29/CE.

De qualquer sorte, independentemente desta alteração legal, a superioridade do limite da cópia privada se interpreta claramente, uma vez que não se admite a substituição da proteção legal desta pela proteção técnica das medidas tecnológicas (RAMALHO, 2011).

Caso bastante peculiar é o da legislação brasileira, que não adotou o Tratado sobre Direitos de Autor da Organização Mundial da Propriedade Intelectual, mas incluiu na última reforma da sua legislação autoral, que data de 1996, em seu art. 107, a regulação das medidas tecnológicas.

No que diz respeito à legislação autoral brasileira, os incisos I e II, do seu art. 107, proíbem a alteração, a supressão, a modificação ou inutilização dos dispositivos técnicos utilizados para evitar ou restringir a cópia ou a comunicação ao público das obras protegidas.

Claramente, deflagra-se do conteúdo da legislação autoral brasileira que esta somente protege as medidas tecnológicas que controlam a cópia e a comunicação pública das obras protegidas pelo direito de autor; deixando de lado a proteção das medidas tecnológicas de acesso.

Ademais, frise-se, que o legislador brasileiro não apresenta qualquer noção do que se compreende como medidas tecnológicas de proteção, inclusive, não utiliza esta denominação, nomeando-as como «dispositivos técnicos».

Registre-se, ainda, que a regulação na lei autoral brasileira destes dispositivos técnicos cinge-se a definir quais são os atos que o utilizador da obra protegida está impedido de realizar quando deseja realizar uma cópia da obra, na qual se inseriu dispositivo técnico. Portanto, como não prevê mecanismo para enfrentar o conflito entra a proteção tecnológica e a fruição dos limites do direito de autor, é bastante incompleta.

$\mathrm{Na}$ verdade, o legislador brasileiro acaba por criar uma contradição no regime jurídico autoral, pois ao não estabelecer nenhum mecanismo, que solucione o conflito entre a proteção dos dispositivos técnicos e os limites do direito de autor, acaba por contrariar o regime de utilização livre previsto na lei e impede a prática de atos legítimos de utilização da obra para uso privado.

Sem embargo, o art. 107 da lei autoral brasileira frontalmente contraria a previsão dos limites do direito de autor estabelecidos nesta norma. Equívoco, que deve ser de pronto corrigido, pois introduz um grande desequilíbrio em face do exclusivo autoral e a fruição, pelos utilizadores de obras protegidas pelo direito de autor, dos limites aos direitos de autor?

9 Refira-se que o projeto de alteração da lei autoral brasileira, reconhecendo o desequilíbrio entre o exclusivo autoral e a fruição dos limites aos direitos de autor, propõe a alteração deste art. 107, de modo a garantir os limites ao direito de autor. Inclusive, determinando a aplicação de sanção a todo aquele que dificultar ou impedir os usos permitidos. Leia-se a proposta de alteração do art. 107: «§1. ${ }^{\circ}$ Incorre na mesma sanção, sem prejuízo de outras penalidades previstas em lei, quem por qualquer meio: a) dificultar ou impedir os usos permitidos pelos artigos 46,47 e 48 desta Lei; ou b) dificultar ou impedir a livre utilização de obras, emissões de radiodifusão e fonogramas caídos em domínio público. $\S 2$. $^{\circ}$ O disposto no caput não se aplica quando as condutas previstas nos incisos I, II e IV relativas aos sinais codificados e dispositivos técnicos forem realizadas para permitir as utilizações previstas nos artigos 46, 47 e 48 desta Lei ou quando findo o prazo dos direitos patrimoniais sobre a obra, interpretação, execução, fonograma ou emissão.» BRASIL. Disponível em: <http://www.planalto.gov.br/ccivil_03/consulta_publica/DireitosAutorais.htm>. 
Refira-se que o projeto de alteração da lei autoral brasileira, reconhecendo o desequilíbrio entre o exclusivo autoral e a fruição dos limites aos direitos de autor, propõe a alteração deste art. 107, de modo a garantir os limites ao direito de autor. Inclusive, determinando a aplicação de sanção a todo aquele que dificultar ou impedir os usos permitidos.

\section{Conclusão}

Ao chegar ao término destas páginas, e com a intenção de estabelecer algumas considerações conclusivas, convém desde logo esclarecer que o presente artigo analisou o uso de medidas tecnológicas de proteção para o controle das utilizações de caráter privado. Pelo que, irrelevante é a identificação do local ou modo que a cópia é realizada.

Desta sorte, para os fins a que se propôs este artigo, importante foi definir o âmbito de atuação do uso privado, delimitando, assim, nesta espécie de utilização o campo de licitude dos atos de neutralização das proteções técnicas, implantadas por mecanismos tecnológicos.

Sem embargo, não restam dúvidas de que a cópia destinada à utilização nos limites do uso privado não se coaduna com o regime jurídico de proteção das medidas tecnológicas.

Evidencia-se, assim, um grande desequilíbrio no regime jurídico das utilizações livres, após a introdução nas legislações autorais de diversas nações, da proteção às medidas tecnológicas que sancionam os atos de neutralização das proteções técnicas.

Verifica-se, também, ser improvável a implementação de medidas tecnológicas eficazes, em função dos elevados custos de investimentos financeiro e de suporte técnico, comparados aos baixos custos de criação dos suportes tecnológicos de neutralização.

$\mathrm{Na}$ verdade, em tempos de inovação tecnológica recorrente, não há medidas tecnológicas infalíveis para o controle dos atos de utilização; mas, tão somente medidas, temporariamente eficazes.

Claro está que o remédio para a redução das utilizações não autorizadas da obra não se pode encerrar na mera utilização de medidas tecnológicas de proteção, pois que o efeito é inverso. $\mathrm{O}$ uso insistente de medidas tecnológicas de controle de acesso e de utilização das obras multiplica o surgimento dos dispositivos de neutralização destas proteções técnicas.

Ademais, deve-se ponderar na análise que a evolução dos mecanismos tecnológicos para o controle dos atos de utilização da obra não é suficiente para distinguir com eficácia o regime jurídico destas utilizações, ou seja, se as utilizações se realizam no âmbito do uso privado ou fora do mesmo.

Outrossim, a mera autorização para a neutralização dos mecanismos tecnológicos de proteção, após a demonstração e verificação em organismo competente de que a utilização da obra se encerra no âmbito do uso privado não se apresenta como solução eficaz. Pois que poucos são os utilizadores das obras que dominarão a capacidade técnica necessária para a neutralização das proteções técnicas.
Acresça-se a isto o fato d e o domínio da técnica necessária para a neutralização das proteções técnicas ser privilégio de poucos, haja vista, a proibição de comercialização de dispositivos técnicos de neutralização. Para além disso, registre-se a incapacidade dos dispositivos de neutralização de identificarem eficazmente se a utilização se realiza no campo da licitude ou da ilicitude.

Desse modo, não é possível concluir que as medidas tecnológicas de proteção sejam eficientes ao ponto de controlar toda e qualquer espécie de utilização, especialmente, identificar e autorizar aquelas realizadas no âmbito do uso privado.

Portanto, o risco de as medidas tecnológicas de proteção afastarem as utilizações permitidas, bem como as facilidades da inovação tecnológica são enormes. A exemplo dos mecanismos de controle de reprodução que bloqueiam a funcionalidade de "copy-paste", dificultando, portanto, o exercício da citação, utilização que se encontra prevista no rol das permitidas, já que no domínio do uso privado.

Assim, certamente, é possível concluir que o regime de proteção das medidas tecnológicas de proteção desequilibra sobremaneira os interesses em jogo, pois que exclui as utilizações permitidas, afastando a cópia privada digital para o limbo jurídico.

\section{Referências}

ASCENÇÃO, J.O. Dispositivos tecnológicos de protecção, direitos de acesso e uso dos bens. Direito da Sociedade da Informação, v.8, p.10, 2009.

ASCENSÃO, J.O. Anais do Fórum Nacional de Direito Autoral - Ministério da Cultura Seminário Internacional sobre Direito Autoral Fortaleza 2008.

BALKIN, J.M. Digital speech and democratic culture: a theory of freedom of expression for the information society. New York University Law Review, v.79, n.1, p.1-58, 2004.

BARRY, M. Cryptography in Home Entertainment. A look at content scrambling in DVDs. 2004. Disponível em: $<$ http://www. math.ucsd.edu/ crypto/Projects/MarkBarry/index.htm>. Acesso em: 17 dez. 2019.

BRASIL. Lei n. ${ }^{\circ}$ 9.610, de 19 de fevereiro 1998. Altera, atualiza e consolida a legislação sobre direitos autorais e dá outras providências. Disponível em: $<$ http://www.planalto.gov.br/ ccivil_03/leis/19610.htm>. Acesso em: 17 dez. 2019.

BRASIL. Projeto de lei que altera e acresce dispositivos à Lei no 9.610, de 19 de fevereiro de 1998, que altera, atualiza e consolida a legislação sobre direitos autorais e dá outras providências. Disponível em: <http://www.planalto.gov.br/ccivil_03/consulta publica/DireitosAutorais.htm>. Acesso em: 17 dez. 2019.

DUSOLLIER, S. Dusollier, Séverine, Droit d'auteur et protection des oeuvres dans l'univers numérique: droits et exceptions à la lumière des dispositifs de verrouillage des oeuvres. Bruxelas: Larcier, 2005.

ESTADOS UNIDOS DA AMÉRICA. Tribunal de Apelações. 2. ${ }^{\circ}$ Circuito. 273 F.3d 429 (2001). Universal City Studios, inc., Paramount Pictures Corporation, Metro-Goldwyn-Mayer Studios Inc., 
Tristar Pictures, Inc., Columbia Pictures Industries, Inc., Time Warner Entertainment Company, L.P., Disney Enterprises Inc., Twentieth Century Fox Film Corporation, Plaintiffs-Appellees, v. Eric CORLEY, also known as Emmanuel Goldstein, and 2600 Enterprises Inc., Defendants-Appellants, United States of America, Intervenor. Docket No. 00-9185. Julgamento em 28.11.2001. Disponível em: <http://scholar.google.com/scholar_case?ca$\mathrm{se}=5930508913825375010 \& \mathrm{q}=273+\mathrm{F} .3 \mathrm{~d}+429 \& \mathrm{hl}=\mathrm{en} \&$ as $\mathrm{sdt}=2002>$. Acesso em: $17 \mathrm{dez} .2019$.

ESTADOS UNIDOS DA AMÉRICA. Tribunal Distrital. Nova York. 111 F.Supp.2d 294 (2000). Universal City Studios, inc., et al., Plaintiffs, v. Shawn C. Reimerdes, et al., Defendants. n. ${ }^{\circ} 00$ Civ. 0277 (LAK). Julgamento em 17.08.2000, Emendado, 06.09.2000. Disponível em: http://scholar.google.com/ scholar_case case $=4887310188384829978 \&$ q $=111+$ F. + Supp. 2d+294\&hl=en\&as_sdt=2002. Acesso em: 17 dez. 2019.

EUROPA. Conselho da Europa. Parlamento Europeu. Diretiva 2001/29/CE, relativa à harmonização de certos aspectos do direito de autor e dos direitos conexos na sociedade da informação. Disponível em: <http://eur-lex.europa.eu/LexUriServ/ LexUriServ.do?uri=OJ:L:2001:167:0010:0019:PT:PDF>.

FERNÁNDEZ-MOLINA, J.C.; PEIS, E. The moral rights of authors in the age of digital information. Journal of the American Society for Information Science and Technology, v.52, n.2, p. 109-117, 2001.

HUGENHOLTZ, P.B.; GUIBAULT, L.; GEFFEN, S. Van. The future of levies in the digital environment. Relatório Final. Amsterdam: Institute for Information Law, 2003.

JOHNSON, B. Apple drops DRM copy protection from millions of iTunes songs. 2009. GMT, San Francisco. Disponível em: http://www.theguardian.com/technology/2009/jan/06/appledrops-itunes-copy-protection. Acesso em: 17 dez. 2019.

KOELMAN, K.J. A hard nut to crack: the protection of technological measures. European Intellectual Property Review, v.22, n.6, p.272-288, 2000.
KOELMAN, K.J. The Protection of Technological Measures vs. The Copyright Limitations. Institute for Information Law, Faculty of Law-University of Amsterdam, 2001. Disponível em: $<$ https://www.i-law.com/ilaw/doc/view.htm?id=499>. Acesso em: 17 dez. 2019.

LESSIG, L. The law of the horse: what cyberlaw might teach. Hard Law Review, v.113, p 501-519, 1999.

LOPES, J.M. La copia privada frente a las medidas tecnológicas de protección. P.E.I. Rev. Propriedade Intelectual, n.20, p.9-76, 2005

LUCAS, A. Droit d'auteur et numérique. Paris: Litec, 1998, p. 274.

O'ROURKE, M.A. Fencing cyberspace: drawing borders in a virtual world. Minnesota Law Review, v.82, n.3, p.609-704, 1998.

ORGANIZAÇÃO MUNDIAL DA PROPRIEDADE INTELECTUAL. 1996. Wipo Copyright Treaty - WCT. Disponível em $<$ http://www.wipo.int/treaties/en/text.jsp?file_id=295166>.

PORTUGAL. Código de Direito de Autor e Conexos de Portugal. Decreto-Lei $n .{ }^{\circ}$ 63/85, 14.03.85. 1985. Disponível em <http:// www.dgpj.mj.pt/sections/leis-da-justica/livro-iii-leis-civis-e/leiscivis/direito-de-autor-e/>.

RAMALHO, A. Análise económica da proteção das medidas tecnológicas no direito de autor: uma visão portuguesa. Rev. Bras. Direito Com. Soc. Liberdade Expressão, v.3. 2011.

SIMÕES, P. As minhas aventuras no reino do IGAC. Disponível em <http://paulasimoesblog.wordpress.com/2008/09/25/asminhas-aventuras-no-reino-da-igac/> Acesso em: 17 dez. 2019.

SIMÕES, P. As minhas aventuras no reino do IGAC II. Disponível em <http://paulasimoesblog.wordpress.com/2008/10/07/asminhas-aventuras-no-reino-da-igac-ii/>, Acesso em: $17 \mathrm{dez}$. 2019.

VICENTE, D.M. Direito de Autor e Medidas Tecnológicas de Proteção. Separata de Direito Comparado Perspectivas LusoAmericanas. v. I, Coimbra; Almedina: 2006, p. 162. 